\title{
Photos provide information on age, but not kinship, of Andean bear
}

Russell C Van Horn, Becky Zug, Robyn D Appleton, Ximena Velez-Liendo, Susanna L Paisley, Corrin LaCombe

Using photos of captive Andean bears of known age and pedigree, and photos of wild Andean bear cubs $<6$ months old, we evaluated the degree to which visual information may be used to estimate bears' ages and assess their kinship. We demonstrate that the ages of Andean bear cubs $\leq 6$ months old may be estimated from their size relative to their mothers with an average error of $<0.01 \pm 13.2$ days (SD; $n=14$ ), and that ages of adults $\geq 10$ years old may be estimated from the proportion of their nose that is pink with an average error of $<0.01 \pm 3.5$ years $(n=41)$. We also show that similarity among the bears' natural markings, as perceived by humans, is not associated with pedigree kinship among the bears $\left(R^{2}<0.001, N=1,043, p=0.499\right)$. Thus, researchers may use photos of wild Andean bears to estimate the ages of young cubs and older adults, but not to infer their kinship. Given that camera trap photos are one of the most readily available sources of information on large cryptic mammals, we suggest that similar methods be tested for use in other poorly understood species. 
2 Russell C. Van Horn ${ }^{1}$, Becky Zug ${ }^{2}$, Robyn D. Appleton ${ }^{3,4}$, Ximena Velez-Liendo ${ }^{5}$, Susanna

3 Paisley $^{6}$, and Corrin LaCombe ${ }^{1,9}$.

$4{ }^{1}$ Institute for Conservation Research, San Diego Zoo Global, San Diego, CA USA

$5 \quad{ }^{2}$ Nelson Institute for Environmental Studies, University of Wisconsin - Madison, WI USA

$6 \quad{ }^{3}$ Department of Forest and Conservation Sciences, University of British Columbia, BC Canada

$7 \quad{ }^{4}$ Spectacled Bear Conservation Society, Squamish, BC Canada

$8{ }^{5}$ Centro de Biodiversidad y Genética, Universidad Mayor de San Simon, Cochabamba, Bolivia

$9 \quad{ }^{6}$ Durrell Institute of Conservation and Ecology, University of Kent, Canterbury, Kent, UK

$10{ }^{9}$ Current affiliation: We Thrive Global, Reno, NV USA

11 Corresponding author:

12 Russell C. Van Horn

13 San Diego Zoo Institute for Conservation Research

14 P.O. Box 120551

15 San Diego, CA 92112-0551 USA

16 Phone: 001-619-231-1515, ext. 4530

17 Email: rvanhorn@sandiegozoo.org 
INTRODUCTION

21 The Andean bear (Tremarctos ornatus, FG Cuvier) is endemic to diverse habitats across a broad

22 latitudinal range in Andean South America but it is vulnerable to extinction (Goldstein et al.

23 2008). Although it is likely that the global population of this bear is declining dramatically due to

24 habitat loss, fragmentation, and poaching (Goldstein et al. 2008), we know little of its ecology

25 (Garshelis 2004), demography (Garshelis 2011), and genetic structuring (Viteri \& Waits 2009),

26 making it difficult to plan for its conservation. To facilitate research in support of Andean bear

27 conservation we've assessed whether we can estimate the ages and assess the kinship of

28 individual Andean bears. Because conservation success may be improved through engagement of

29 local people (Byers 1999; Danielsen et al. 2007; Peyton 1989), and because local people may

30 have knowledge and skills beneficial to scientific research (Sharma, Jhala \& Sawarkar 2005;

31 Stander et al. 1997; Zuercher, Gipson \& Stewart 2003), we've focused on methods that rely on a

32 minimum of technology.

33 Individual appearance may provide information not only on identity (e.g., Van Horn et al.

34 2014) but also on age and even kinship, in species as disparate as giraffe (Giraffa

35 camelopardalis; Berry \& Bercovitch 2012; Foster 1966) and lions (Panthera leo; Whitman et al.

36 2004). Age in other bears has been inferred, with some error, by morphological measurements

37 and dental cementum annuli (Bridges, Olfenbuttel \& Vaughan 2002; Christensen-Dalsgaard et al.

38 2010; Costello et al. 2004; Marks \& Erickson 1966; McLaughlin et al. 1990; Medill et al. 2009;

39 Mundy \& Fuller 1964; Stoneberg \& Jonkel 1966; Willey 1974), but noninvasive methods of age

40 estimation have not been developed for bears. It appears that the markings of some young

41 Andean bears may become less prominent during maturation and that many Andean bears grizzle 
42 during aging, but such changes are not obviously consistent or predictable enough to allow age

43 estimation (Van Horn et al. 2014). In addition, because monitoring the changes in markings

44 would require repeated assessments across years, monitoring those changes to estimate age

45 would not be feasible for short-term or cross-sectional demographic research. Because the point-

46 in-time estimated size of offspring relative to their mothers may predict their age (e.g., Jongejan,

47 Arcese \& Sinclair 1991), we evaluated whether such data predicted the ages of young Andean

48 bear cubs. In addition, because point-in-time samples of nose color are a reliable but potentially

49 sexually-dimorphic indicator of age in another carnivore (Panthera leo, Whitman et al. 2004),

50 we examined the degree to which the nose color of Andean bears reflected their age. Genetic

51 analysis would provide strong evidence of kinship (e.g., Woods et al. 1999) and genetic tools are

52 being developed for Andean bears (e.g., Viteri \& Waits 2009), but collection of genetic samples

53 is not always feasible in the humid tropical forests and grasslands where most Andean bears are

54 thought to live (Goldstein et al. 2008). Aside from genetic data, kinship may be inferred from

55 similarity of appearance among individuals in some species in some studies (Pan troglodytes,

56 Gorilla gorilla, Mandrillus sphinx, and Papio ursinus, Alvergne et al. 2009; Cygnus

57 columbianus, Bateson, Lotwick \& Scott 1980; Acinonyx jubatus, Caro \& Durant 1991;

58 Macropus giganteus, M. rufogriseus, Jarman et al. 1989; P. troglodytes, Parr \& De Waal 1999;

59 Vokey et al. 2004), but not in others (A. jubatus, Kelly 2001). The inheritance of markings

60 among bears is poorly understood (Higashide, Miura \& Miguchi 2012) and there is some

61 evidence that patterns in markings of Andean bears are not obviously heritable (Eck 1969), so

62 the link between kinship and similarity in markings among Andean bears is uncertain, at best.

63 We therefore assessed whether this link is informative. If information on an Andean bear's age 
64 and kinship can be extracted from its appearance, then non-invasive methods such as camera

65 traps may provide elusive information that is valuable for conservation.

66

\section{MATERIALS AND METHODS}

69 We extracted information from portraits of captive Andean bears of known identity, age, and

70 pedigree that were posted online, and from zoo personnel and field researchers in North America, 71 Europe, and South America (Van Horn et al. 2014). If we did not know the date on which the 72 photograph was taken, we assigned it the midpoint of the time period in which the photo was 73 taken (e.g., photos taken in 'July' were assigned the date 15 July).

\section{Visual estimation of age through relative body size}

76 To evaluate whether the relative size of young cubs might predict their age, we extracted 77 information from opportunistically-collected photographs of known-age cubs born in captivity, 78 and from young cubs found in their natal dens in the tropical dry forest of northwest Peru $79\left(^{\circ} 26^{\prime} \mathrm{S}, 79^{\circ} 33^{\prime} \mathrm{W}\right)$, where research on Andean bear ecology and behavior has been underway 80 since 2007. We located active natal dens by inferring den entry from the sudden cessation of new 81 telemetry positions and by then searching near the last previous transmitted locations, along with 82 searching similar sites during the same season. We estimated the ages of cubs found in their natal 83 dens from their development (e.g., ability to lift head, eyes closed or open, ability to stand, 84 ability to walk), when compared to published descriptions of captive cub development (Aquilina 85 1981; Bloxam 1977; Malzacher \& Hall 1998; Molloy 1989; Müller 1988; Peel, Price \& Karsten 86 1979; Saporiti 1949; Stancer 1990). We later opportunistically collected photos of some of these 
87 same wild cubs and their mothers with camera traps set during a long-term study. Within those

88 camera trap photos we measured the size of cubs, relative to the size of their mothers, for wild-

89 born and captive-born cubs that were $<180$ days old. We chose this criterion as a conservative

90 estimate of the age period within which the growth of male and female bears appears similar and

91 approximately linear (Bartareau et al. 2012; Blanchard 1987; Bridges et al. 2002; Kingsley 1979;

92 McRoberts, Brooks \& Rogers 1998) and because growth among older cubs might be influenced

93 by factors other than age (e.g., seasonal or interannual variation in food availability). To avoid

94 potentially confounding variation that might be introduced by variation in litter size we also

95 excluded data from twin litters. We estimated the relative sizes of cubs by taking the mean of

96 three replicate measures of the same fixed post-cranial measurement of cubs and their mothers

97 when they were the same distance from the camera, as determined by visual landmarks in the

98 photographs ( $\mathrm{n}=14,2.0 \pm 1.3$ photos/mother-cub pair). Each of the three replicate measures was

99 itself the mean of three measurements by each of three observers. To reduce the impact of

100 measurement error we only estimated the relative size of limb segments that we thought would

101 be most visibly discrete (i.e., clearly defined by joint or bone protuberance) and repeatable

102 between cubs and their mothers. We excluded photographs in which matching measurements

103 could not be made on both a cub and its mother; due to the opportunistic nature of the

104 photographs those measurements differed among mother-cub pairings: lower hindleg $(n=6)$,

105 lower foreleg $(n=4)$, shoulder height $(n=3)$, and upper hindleg $(n=1)$. We constructed

106 candidate predictive models of relative cub size from cub age (69 - 180 days), cub provenance

107 (captive-born or wild-born), cub identity (4 captive-born, 3 wild-born), and the interaction

108 between cub identity and age. We then used an information theoretic approach (Burnham \&

109 Anderson 2002) to compare the candidate models using $\mathrm{AIC}_{\mathrm{c}}$ as the key criterion for model 
110 selection, and we used $\mathrm{R}^{2}$ and $\mathrm{p}$ to assess the effectiveness of the 'best' model for describing a

111 cub's relative size.

112

113 Visual estimation of age through nose color

114 To investigate the relationship between the color of a bear's nose and its age (years) we first

115 screened photos of captive Andean bears to exclude photos that did not show the entire nose,

116 photos that did not appear in focus when magnified to $2-4 \mathrm{X}$, and photos from which there were

$117<1000$ pixels in the image of the nose. To avoid non-independence between photos we excluded

118 multiple photos of the same bear that were taken within 365 days, and we renamed the 76

119 remaining photos from 58 bears (32M, 26F), aged $0.3-31.4$ years, with random numbers. We

120 then expressed the color of a bear's nose as the proportion of the area of the nose that was pink

121 ('proportion pink') by taking the mean of three independent replicate estimates by the same

122 observer (i.e., the lead author) of the proportional area of pink in each photo, excluding the

123 nostrils (which were often shaded), and excluding pink scar tissue. We had longitudinal series of

124 photos from 10 bears $(7 \mathrm{M}, 3 \mathrm{~F})$ that provided 12 pairwise within-individual comparisons of the

125 change in nose color over time; the average annual change in the proportion pink was $0.02 \pm$

1260.02 , which lent credence to the use of proportion pink as an indicator of age. Because there were

127 multiple photographs for some but not all bears ( $1.31 \pm 0.6$ photos/bear), to avoid non-

128 independence of data and to allow for model testing we randomly selected 1 photograph per bear

129 from photographs of bears $\geq 9.9$ years old (the minimum age at which we observed pink on the

130 nose) for use in model building and retained the other data in this age range for use in model

131 testing. We then used the proportion pink as the response variable in linear regression analyses

132 with candidate models including age, sex, and the interaction of age and sex. We used $\mathrm{AIC}_{\mathrm{c}}$ as 
133 the key criterion for model selection, with $\mathrm{R}^{2}$ and $\mathrm{p}$ to assess the effectiveness of the 'best' model

134 for describing the proportion of the nose that was pink. When multiple candidate models were

135 competitive (i.e., $\triangle \mathrm{AICc} \leq 2$ ), we used full model averaging (e.g., Lukacs, Burnham \& Anderson

1362009 ) to derive the predictive equation including age, sex, and the interaction of age and sex. To

137 assess the fit and putative power of relationships predicting age we then examined the reverse

138 relationships, with age as the response variable, and examined the distribution of the relevant

139 residuals. When possible we tested the ability of equations to predict the ages of bears in images

140 that had not been used to describe the relationship between age and nose color.

\section{Similarity of markings and kinship}

143 To assess humans' ability to visually evaluate kinship among Andean bears, as part of a

144 larger study we created an online survey and sought volunteer participation by colleagues, peers,

145 personal contacts, and a solicitation in the International Bear News (Paisley et al. 2010; Van

146 Horn et al. 2014). We asked participants to rate the similarity of 11 pairs of images of bears

147 whose kinship was unknown to them; the average pedigree r-values across these pairs of images

148 was $0.32 \pm 0.23$. Participants were asked to rate the similarity of the markings of bears in these

149 images as 1 of 5 categories: exactly the same, similar, slightly different, extremely different, and

150 unable to determine. Participants $(n=109)$ in the online survey rated the similarity of, on

151 average, $9.6 \pm 1.7$ of 11 pairs of images. We used ordinal logistic regression to examine the

152 strength of the relationship between the perceived visual similarity of markings and the pedigree

$153 \mathrm{r}$-values of the bears in the images with candidate models including pedigree r-values, whether

154 the participant had experience working with Andean bears $(n=10)$ or not $(n=99)$, and the

155 interaction of pedigree r-value and experience. We used $\mathrm{AIC}_{\mathrm{c}}$ as the key criterion for model 
156 selection, with $\mathrm{R}^{2}$ and $\mathrm{p}$ to assess the effectiveness of the 'best' model for describing the

157 relationship between perceived visual similarity and the pedigree r-values.

158 Unless otherwise noted all quantities are expressed as $\bar{x} \pm \mathrm{SD}$, and statistical significance

159 refers to two-tailed $\mathrm{p}=0.05$. Statistical analyses were conducted in JMP 10.0.2 (SAS Institute

160 Inc., Cary, NC). Animal research was approved by the IACUC committee of San Diego Zoo

161 Global (\#10-023).

162

163

\section{RESULTS}

\section{Visual estimation of age through relative body size}

166 The model which described cub relative size from only an intercept and cub age in days $\left(\mathrm{R}^{2}=\right.$

$1670.835, \mathrm{DF}=13, p<0.001)$ fit the data better than all other models that included combinations of

168 cub identity, cub provenance, and an interaction term (i.e., $\Delta \mathrm{AICc}>4$ ): relative size $=0.123+$

$1690.003 *$ (age in days). This model would not perform well for much younger and older cubs, as it

170 predicts that newborn cubs are $12.3 \%$ of their mother's size and that cubs would be the same size

171 as their mothers when only 313 days old, but from $2-6$ months in age there appears to be a

172 linear relationship between cub age and relative size (Fig. 1). The reverse relationship is (age in

173 days $)=-15.263+293.26 *($ relative size $)$, from which the average residual was $1.32 \times 10^{-14} \pm 13.2$

174 days.

175

176 Visual estimation of age through nose color

177 No pink was seen on the nose in 26 photos of 20 bears (10M, 10F), of which all but one $(96.1 \%)$

178 were $<10$ years old; the youngest age at which we saw pink on the nose was 9.9 years $(\mathrm{n}=50$ 
179 photos, $16.54 \pm 14.7 \%$ pink; Fig. 2). Nearly all of the 52 photos of bears $>9.5$ years old $(96.2 \%)$

180 showed some pink on the nose. There was variation among the repeated estimates of the

181 proportion pink from those photographs (i.e., average SD of proportion pink across repeated

182 estimates $=2.1)$. The linear model, built upon data from 41 photos of 41 bears $(23 \mathrm{M}, 18 \mathrm{~F})$,

183 which best fit the data predicted the proportion pink from only age $\left(\mathrm{R}^{2}=0.554, \mathrm{DF}=39, p<\right.$

1840.001 ) but there were two other competitive models (i.e., $\Delta \mathrm{AICc}>2$ ): the model that also

185 included sex, and the model that included sex and the interaction of sex and age. We therefore

186 used model averaging to derive the equation (proportion pink) $=-0.257+0.022 *$ (age in years) +

$1870.0006^{*}(\text { age in years })^{*}(\mathrm{z})$ where $\mathrm{z}=0$ if male or $\mathrm{z}=1$ if female. However, in practice it will not

188 always be possible to determine the sex of a bear from camera trap photos. The best predictive

189 model for bears of unknown sex predicted the (proportion pink) $=-0.254+0.022 *($ age in years).

190 In reverse, this relationship predicted (age in years) $=15.055+25.129 *$ (proportion pink) with an

191 average residual of $2.99 \times 10^{-15} \pm 3.46$ years. Testing this model with the 7 independent data

192 points $(6 \mathrm{M}, 1 \mathrm{~F})$ yielded an average error of $-1.62 \pm 2.3$ years. Using the 23 points from males in

193 the model-building data set, we found that for males (proportion pink) $=-0.156+0.018 *$ (age in

194 years $)\left(\mathrm{R}^{2}=0.335, \mathrm{DF}=22, \mathrm{p}=0.004\right)$. The reverse of this relationship predicted age (in years)

195 of males as $15.482+10.698 *$ (proportion pink) with an average residual of $2.39 \times 10^{-15} \pm 3.2$

196 years. Testing this model with the 6 independent data points from males produced an average

197 error of $-2.43 \pm 2.7$ years. Using the 18 points from females in the model-building data set, we

198 found that among females the (proportion pink) $=-0.33+0.0245^{*}$ (age in years) $\left(\mathrm{R}^{2}=0.703, \mathrm{DF}\right.$

$199=17, \mathrm{p}<0.001)$. The reverse relationship predicted for females that (age in years) $=15.435+$

$20028.644 *$ (proportion pink) with an average residual of $-1.28 \times 10^{-15} \pm 3.7$ years. With only 1 
201 independent data point from a female we cannot further assess the errors in age estimation that 202 result from this model.

203

\section{Similarity of markings and kinship}

205 Markings of Andean bears vary greatly even among full siblings (e.g., Fig. 3). The average

206 pedigree r-values across pairs of test images was between the kinship levels of half-siblings and

207 full-siblings, yet the average similarity rating given to these paired images by participants was

$2083.38 \pm 0.85$, between 'slightly different' (i.e., '3') and 'extremely different' (i.e., '4'). There was

209 not a meaningful relationship between the pedigree r-values of bears and similarity rankings of

210 their photos across all participants $\left(\mathrm{R}^{2}<0.001, \mathrm{~N}=1,043, \mathrm{p}=0.499\right)$, among the participants

211 who had worked with Andean bears $\left(\mathrm{R}^{2}<0.001, \mathrm{~N}=98, \mathrm{p}=0.843\right)$, or among the participants

212 who had not worked with Andean bears $\left(\mathrm{R}^{2}<0.001, \mathrm{~N}=945, \mathrm{p}=0.436\right)$. In addition, the model

213 which best described the relationship between pedigree r-values of bears and similarity rankings

214 of their photos included only an intercept term. Models including either pedigree $r$ or experience

215 working with Andean bears were also both competitive (i.e., $\Delta \mathrm{AICc}<2$ ) but none of these three

216 models fit the data well (i.e., each had $\mathrm{R}^{2}<0.001$ ). Thus, there is no evidence that similarity

217 among paired images, as perceived by experienced or inexperienced participants, reflected

218 pedigree kinship among the bears.

219

220 DISCUSSION

222 By reviewing photos of cubs $<6$ months old we found that for the first several months after

223 young Andean bears leave their natal dens, the relative size of cubs can be used to predict their 
224 age and then estimate their birthdates. At present the only data on birthdates of Andean bears

225 come from captivity (e.g., Spady, Lindberg \& Durrant 2007) and from 2 dens in Ecuador

226 (Castellanos 2010, 2015), so the estimation of any additional birthdates of wild cubs should offer

227 important insights into Andean bear reproductive ecology. Interestingly, because the provenance

228 of young cubs had no impact on their relative growth, relative growth of young cubs should be

229 stable across habitats, allowing the use of this relationship to predict ages and estimate birthdates

230 across the species' range. Given that a similar method of age estimation is effective in a

231 phylogenetically distant species (Ourebia ourebi, Jongejan, Arcese \& Sinclair 1991), we think

232 the relative size of dependent offspring may be a useful way for investigators to visually estimate

233 the ages and birthdates of progeny in many other species.

234 Nose color provides a clear noninvasive indicator of whether an Andean bear is older or 235 younger than 10 years: if any of the nose is pink the bear is almost certainly $>10$ years old, and

236 vice versa. We do not know whether Andean bears begin undergoing other physiological,

237 behavioral, or ecological changes at this age, but older Andean bears also show grizzling on their

238 faces (Van Horn et al. 2014). Using the proportion pink of the bear's nose, and whatever

239 information is available about a bear's sex, we can estimate the age of a wild Andean bear to \pm 3

$240-4$ years. Because we did not have independent samples for model building and testing, we

241 cannot predict well the precision of age estimates generated with other sample sets, but these

242 estimates are less precise than age estimates for some other bear species (e.g., Christensen-

243 Dalsgaard et al. 2010; Costello et al. 2004). However, those estimates require capture and

244 handling of the bear, while measuring nose color does not. It may not be easy to obtain many

245 suitable photos of the noses of free-ranging bears without the use of lures and relatively complex

246 configurations of cameras traps, but two of us (RVH, RDA) have done so. We do not know if 
247 nose color changes in a predictable manner in other bears and in other carnivores except lions

248 (Whitman et al. 2004), although we have seen photos of some cats (e.g., Leopardus pardalis,

249 Puma concolor) showing variation in their nose color. We therefore suggest that nose color may

250 provide valuable information on age structure in other carnivores.

251 Our data indicate that it is not possible to infer kinship among Andean bears based on the

252 perceived similarity of their markings. This is consistent with Eck's (1969) hypothesis that

253 patterns in markings are not heritable and this affirms that genetic tools (e.g., Viteri \& Waits

254 2009) are needed to infer kinship among wild Andean bears.

255 Although the methods we describe cannot replace long-term research on known individuals,

256 we believe that they will facilitate the collection of data and enhance the value of camera

257 trapping efforts for the conservation of Andean bears. Because these methods require relatively

258 little advanced technology or training, we hope that they will permit the engagement of local

259 people in this research. In addition, we believe the examination of the relationships among

260 relative size, nose color, sex, and age among known-age individuals of other species may

261 produce similarly useful methods across more taxa.

\section{ACKNOWLEDGEMENTS}

265 We thank the Smithsonian's National Zoo and the following for the use of their photographs in 266 Figure 3: Daniel Reidel ('Billie Jean', 'Chaska', and 'Nicole'), Tracey Barnes ('Bernardo' and 267 'Curt'), and Valerie Abbott ('Nikki'). We thank Drs. Peter Arcese and Ron Swaisgood for their 268 intellectual contributions. We thank the volunteer participants in the online survey, which was 269 made possible by Yuri Nataniel Daza (Universidad de San Simon). The following zoological 
270 gardens and individuals shared photographs of captive Andean bears for use in the online survey:

271 Antwerp Zoo (Sander Hofman), Basel Zoo (Dr. Friederike von Houwald), Brookfield Zoo,

272 Cheyenne Mountain Zoo, Cincinnati Zoo, Cleveland Metroparks Zoo, Connecticut's Beardsley

273 Zoo, Dortmund Zoo (Dr. Florian Sicks), Durrell Wildlife Conservation Trust (Mark Brayshaw),

274 Gladys Porter Zoo, Houston Zoo, Köln Zoo (Dr. Lydia Kolter), Minnesota Zoo, Oglebay's Good

275 Zoo, Racine Zoo, Reid Park Zoo, Rolling Hills Wildlife Adventure, Salisbury Zoo, San Antonio

276 Zoo, San Diego Global, Smithsonian National Zoo, and Smoky Mountain Zoo. We were able to

277 collect data on wild Andean bears only through the efforts of Javier Vallejos, José Vallejos, and

278 Isai Sanchez. We thank the citizens of the Rio La Leche watershed for permission and support to

279 work on communal land. Governmental permission to conduct field research was granted by the

280 Dirección General Forestal y de Fauna Silvestre as Resolución Directoral No. 0245-2012-AG-

281 DGFFS-DGEFFS.

282 


\section{REFERENCES}

285

286

287

288

289

290

291

292

293

294

295

296

297

298

299

300

301

302

303

304

305

Alvergne A, Huchard E, Charpentier MJE, Setchell JM, Ruppli C, Féjan D, Martinez L, Cowlishaw G, Raymond M. 2009. Human ability to recognize kin visually within primates. International Journal of Primatology 30:199-210.

Aquilina GD. 1981. Stimulation of maternal behaviour in the Spectacled bear Tremarctos ornatus at Buffalo Zoo. International Zoo Yearbook 21:143-145.

Bartareau TM, Larter NC, Cluff HD, Leone EH. 2012. Body condition and growth dynamics of American black bears in northern Canada. Ursus 23:12-20.

Bateson P, Lotwick W, Scott DK. 1980. Similarities between the faces of parents and offspring in Bewick's swan and the differences between mates. Journal of Zoology 191:61-74

Berry PSM, Bercovitch FB. 2012. Darkening coat colour reveals life history and life expectancy of male Thornicroft's giraffes. Journal of Zoology 287:157-160.

Blanchard BM. 1987. Size and growth patters of the Yellowstone grizzly bear. International Conference on Bear Research and Management 7:99-107.

Bloxam Q. 1977. Breeding the spectacled bear Tremarctos ornatus at Jersey Zoo. International Zoo Yearbook 17:158-161.

Bridges AS, Olfenbuttel C, Vaughan MR. 2002. A mixed regression model to estimate neonatal black bear cub age. Wildlife Society Bulletin 30:1253-1258.

Burnham KP, Anderson DR. 2002. Model selection and multimodel inference: a practical information-theoretic approach. 2nd edition. New York, NY: Springer Science + Business Media. 
306 Byers T. 1999. Perspectives of aboriginal people on wildlife research. Wildlife Society Bulletin 27:671-675.

308 Caro TM, Durant SM. 1991. Use of quantitatve analyses of pelage characteristics to reveal 309 family resemblances in genetically monomorphic cheetahs. Journal of Heredity 82:8$310 \quad 14$.

311 Castellanos A. 2010. Andean bear den found in Ecuador cloud forest. International Bear News 19:6-8.

313 Castellanos A. 2015. Maternal behavior of a female Andean bear in the paramo of Cayambe Coca National Park, Ecuador. International Bear News 24:32-33.

315 Christensen-Dalsgaard SN, Aars J, Andersen M, Lockyer C, Yoccoz NG. 2010. Accuracy and precision in estimation of age of Norwegian Arctic polar bears (Ursus maritimus) using dental cementum layers from known-age individuals. Polar Biology 33:589-

Costello CM, Inman KH, Jones DE, Inman RM, Thompson BC, Quigley HB. 2004. Reliability of the cementum annuli technique for estimating age of black bears in New Mexico. Wildlife Society Bulletin 32:169-176.

Danielsen F, Mendoza MM, Tagtag A, Alviola PA, Balete DS, Jensen AE, Enghoff M, Poulsen MK. 2007. Increasing conservation management action by involving local people in natural resource monitoring. Ambio 36:566-570.

325 Eck S. 1969. Über das Verhalten eines im Dresdener Zoologischen Garten aufgezogenen Brillenbären (Tremarctos ornatus [Cuv.]). Der Zoologische Garten 37:81-92.

327 Foster JB. 1966. The giraffe of Nairobi National Park: home range, sex ratios, the herd, and food. East African Wildlife Journal 4:139-148. 
329 Garshelis DL. 2004. Variation in ursid life histories: is there an outlier? In: Lindburg D, and 330 Baragona K, eds. Giant pandas: biology and conservation. Berkeley and Los Angeles: $331 \quad$ University of California Press, 53-73.

332 Garshelis, DL. 2011. Andean bear density and abundance estimates - How reliable and 333 useful are they? Ursus 22:47-64

334 Goldstein I, Velez-Liendo X, Paisley S, Garshelis DL. (IUCN SSC Bear Specialist Group). 2008.

335 Tremarctos ornatus. The IUCN Red List of Threatened Species. Available at 336 www.iucnredlist.org (accessed 3 January 2014.)

337 Higashide D, Miura S, Miguchi H. 2012. Are chest marks unique to Asiatic black bear 338 individuals? Journal of Zoology 288:199-206.

Jarman PJ, Jones ME, Southwell CJ, Stuartdick RI, Higginbottom KB, Clark JL. 1989. Macropod studies at Wallaby Creek VIII. Individual recognition of kangaroos and wallabies. Australian Wildlife Research 16:179-185.

342 Jongejan G, Arcese P, Sinclair ARE. 1991. Growth, size and the timing of births in an individually identified population of oribi. African Journal of Ecology 29:340-352.

344 Kelly MJ. 2001. Computer-aided photograph matching in studies using individual identification: an example from Serengeti cheetahs. Journal of Mammalogy 82:440-

Kingsley MCS. 1979. Fitting the von Bertalanffy growth equation to polar bear age-weight 348 data. Canadian Journal of Zoology 57:1020-1025.

Lukacs PM, Burnham KP, Anderson DR. 2009. Model selection bias and Freedman's 350 paradox. Annals of the Institute of Statistical Mathematics 62:117-125. 
351 Malzacher H, Hall D. 1998. Hand-raising spectacled bear cubs at Henry Vilas Zoo, Madison, 352 Wisconsin. In: Rosenthal MA, ed. International Studbook for the Spectacled Bear. Chicago, IL: Lincoln Park Zoological Gardens, 169-178.

354 Marks SA, Erickson AW. 1966. Age determination in the black bear. Journal of Wildlife Management 30:389-410.

356

McLaughlin CR, Matula GJ, Cross RA, Haltman WH, Caron MA, Morris KI. 1990. Precision and accuracy of estimating age of Maine black bears by cementum annuli. International Conference on Bear Research and Management 8:415-419.

McRoberts RE, Brooks RT, Rogers LL. 1998. Using nonlinear mixed effects models to estimate size-age relationships for black bears. Canadian Journal of Zoology 76:1098-1106.

Medill S, Derocher AE, Stirling I, Lunn N, Moses RA. 2009. Estimating cementum annuli width in polar bears: identifying sources of variation and error. Journal of Mammalogy 90:1256-1264.

Molloy LM. 1989. Mother-rearing in captive spectacled bear (Tremarctos ornatus) through the use of video tape. Proceedings of the First International Symposium on the Spectacled Bear. Lincoln Park Zoological Gardens, Chicago, IL.: Lincoln Park Zoological Gardens, Chicago, IL. p 189-208.

Müller P. 1988. Beobachtungen zur Fortpflanzungsbiologie von Brillenbären, Tremarctos ornatus (F. Cuvier, 1825), im Zoologischen Garten Leipzig. Der Zoologische Garten $58: 9-21$.

Mundy KRD, Fuller WA. 1964. Age determination in the grizzly bear. Journal of Wildlife Management 28:863-866. 
374 Paisley S, Van Horn R, Velez-Liendo X, Zug B. 2010. Facial markings of Andean bears - can

375 you tell one from another? International Bear News 19:26.

376 Parr LA, de Waal FBM. 1999. Visual kin recognition in chimpanzees. Nature 399:647-648.

377 Peel RR, Price J, Karsten P. 1979. Mother-rearing of a spectacled bear cub Tremarctos

$378 \quad$ ornatus at Calgary Zoo. International Zoo Yearbook 19:177-182.

379 Peyton B. 1989. The ecology of conservation: a case for an ecosystem approach. In:

380 Rosenthal MA, ed. Proceedings of the First International Symposium on the Spectacled

381 Bear. Chicago, IL: Lincoln Park Zoological Society, 74-91.

382 Saporiti EJ. 1949. Contribución al conocimiento de la biología del oso de lentes. Anales de la $383 \quad$ Sociedad Científica Argentina 147:3-12.

384 Sharma S, Jhala Y, Sawarkar VB. 2005. Identification of individual tigers (Panthera tigris) 385 from their pugmarks. Journal of Zoology 267:9-18.

386 Spady TJ, Lindberg DG, Durrant BS. 2007. Evolution of reproductive seasonality in bears. $387 \quad$ Mammal Review 37:21-53.

388 Stancer M. 1990. Pepino: San Diego Zoo's first hand-reared spectacled bear. In: Rosenthal 389 MA, ed. International register and studbook for the spectacled bear (Tremarctos 390 ornatus). Chicago, IL: Lincoln Park Zoological Gardens, 75-82.

391 Stander PE, Ghau I, Tsisaba D, łoma l, Ui ll. 1997. Tracking and the interpretation of spoor: 392 a scientifically sound method in ecology. Journal of Zoology, London 242:329-341.

393 Stoneberg RP, Jonkel CJ. 1966. Age determination of black bears by cementum layers. $394 \quad$ Journal of Wildlife Management 30:411-414. 
395 Van Horn RC, Zug B, LaCombe C, Velez-LIendo X, Paisley S. 2014. Human visual

396

397 identification of individual Andean bears Tremarctos ornatus. Wildlife Biology

398 Viteri MP, Waits LP. 2009. Identifying polymorphic microsatellite loci for Andean bear 399 research. Ursus 20:102-108.

400 Vokey JR, Rendall D, Tangen JM, Parr LA, de Waal FBM. 2004. Visual kin recognition and 401 family resemblence in chimpanzees (Pan troglodytes). Journal of Comparative $402 \quad$ Psychology 118:194-199.

403 Whitman K, Starfield AM, Quadling HS, Packer C. 2004. Sustainable trophy hunting in $404 \quad$ African lions. Nature 428:175-178.

405 Willey CH. 1974. Aging black bears from first premolar tooth sections. Journal of Wildlife $406 \quad$ Management 38:91-100.

407 Woods JG, Paetkau D, Lewis D, McLellan BN, Proctor M, Strobeck C. 1999. Genetic tagging of 408 free-ranging black and brown bears. Wildlife Society Bulletin 27:616-627.

409 Zuercher GL, Gipson PS, Stewart GC. 2003. Identification of carnivore feces by local peoples $410 \quad$ and molecular analyses. Wildlife Society Bulletin 31:961-970. 
1

The size of Andean bear cubs in proportion to the size of their mothers, while the cubs were 2-6 months old.

The dashed line illustrates the linear regression of average relative size in response to age in days among 4 captive-born (open circles) and 3 wild-born (filled circles) cubs.

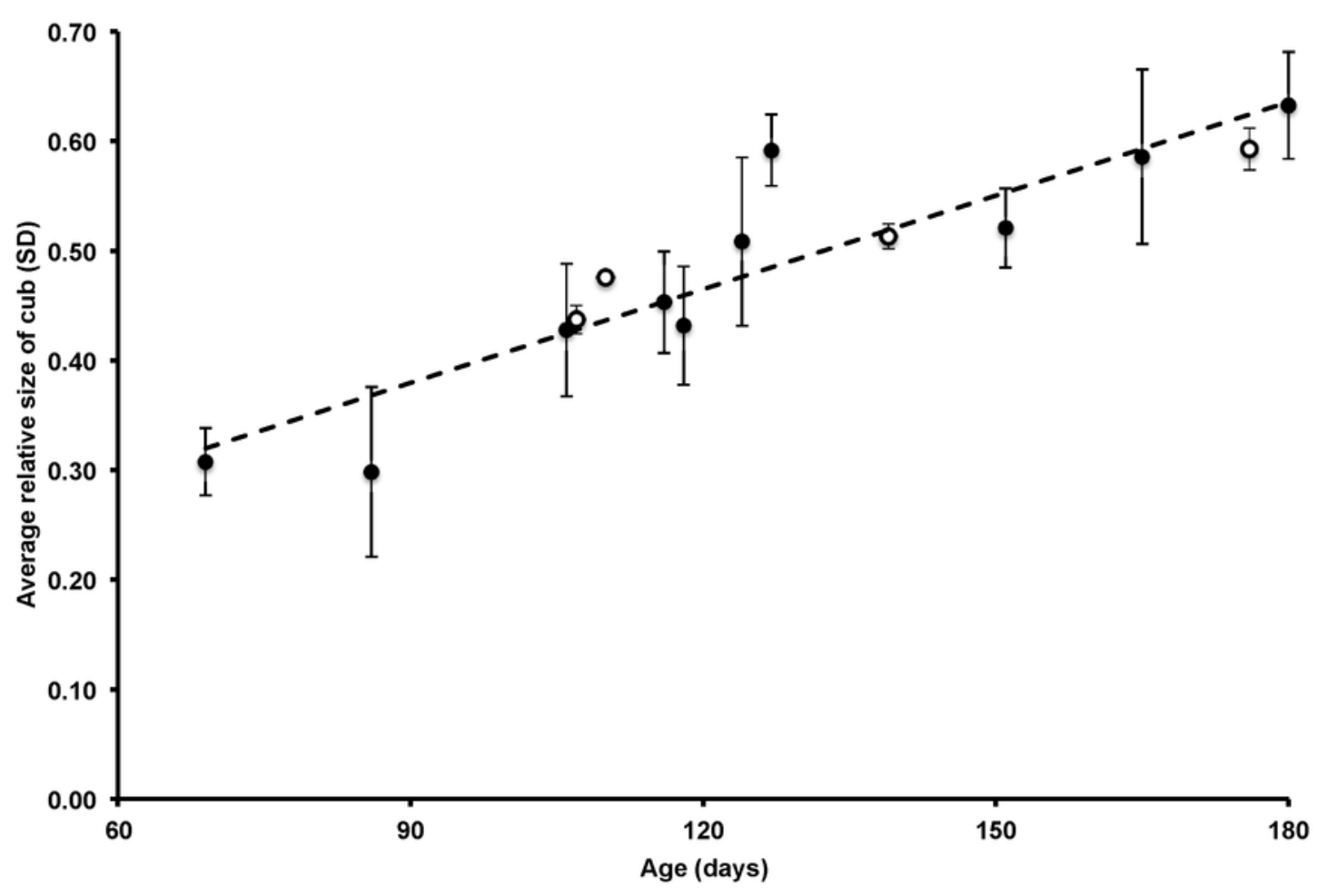


2

The proportion pink of an Andean bear's nose across age in (A) a male Andean bear ('Tommy', studbook \#264), aged 2, 17, and 23 years, and (B) in 76 photos of 58 captive-born Andean bears (32M, 26F).

The trendlines show the relationships between the proportion pink and age in males (open square, dashed line) and females (filled circle, solid line). 

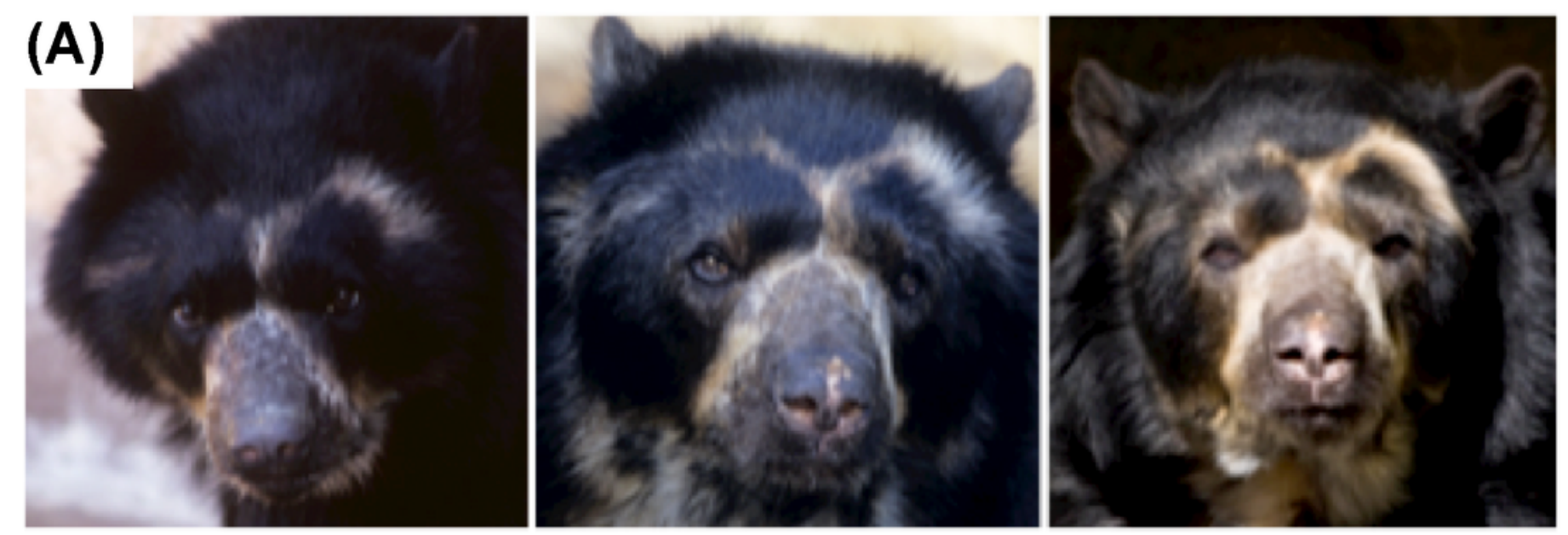

(B)

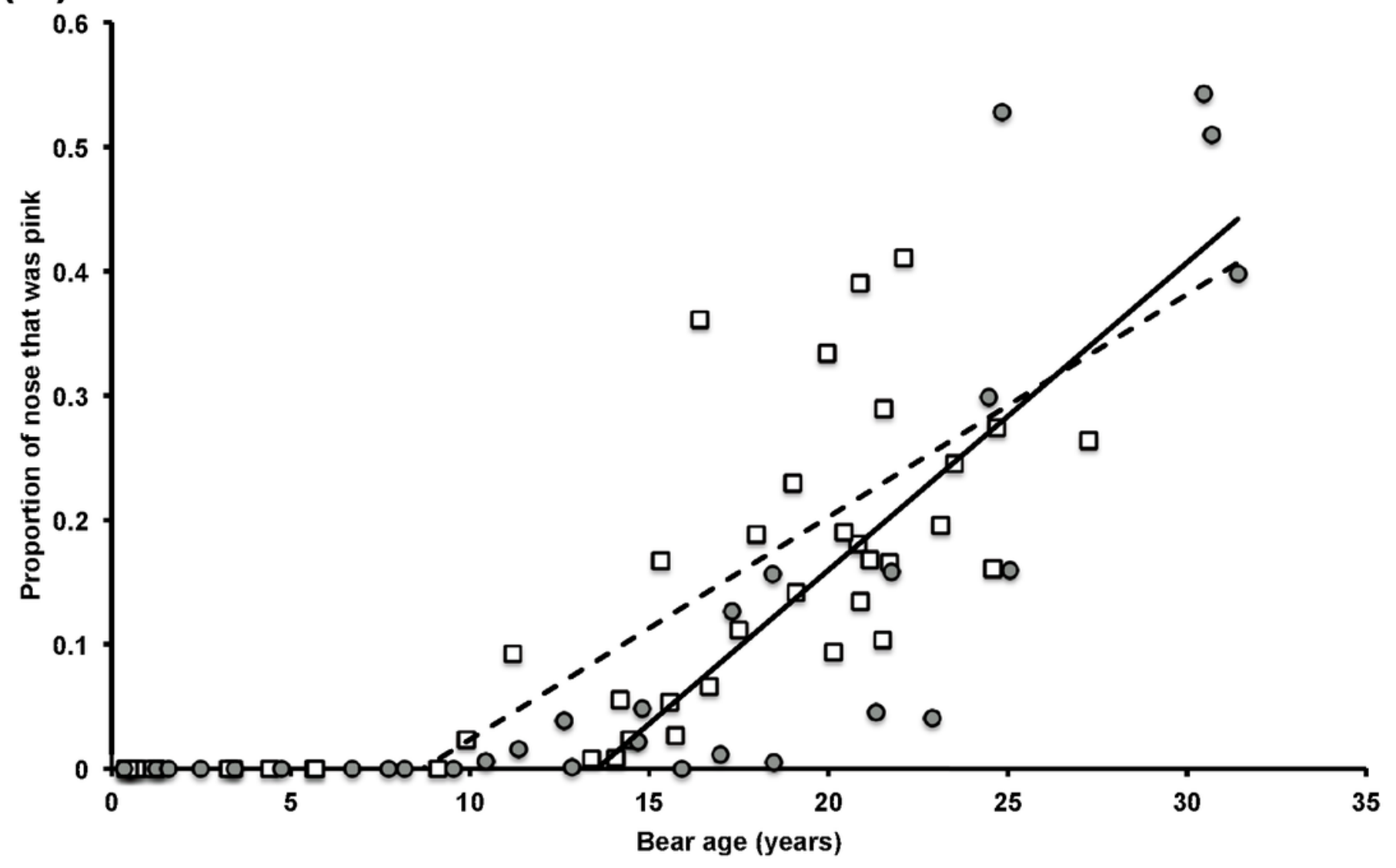




\section{3}

A photographic pedigree of captive-born Andean bears.

Squares represent males and circles represent females in this pedigree of male 'Nikki' (studbook \#415, 19.3 years old), his mate 'Billie Jean' (studbook \#748, 7.4 years old), and their four offspring: the littermates 'Bernardo' (studbook \#837, 1.2 years old) and 'Chaska' (studbook \#838, 3.3 years old), and the littermates 'Curt' (studbook \#860, 2.0 years old) and 'Nicole' (studbook \#861, 1.3 years old).

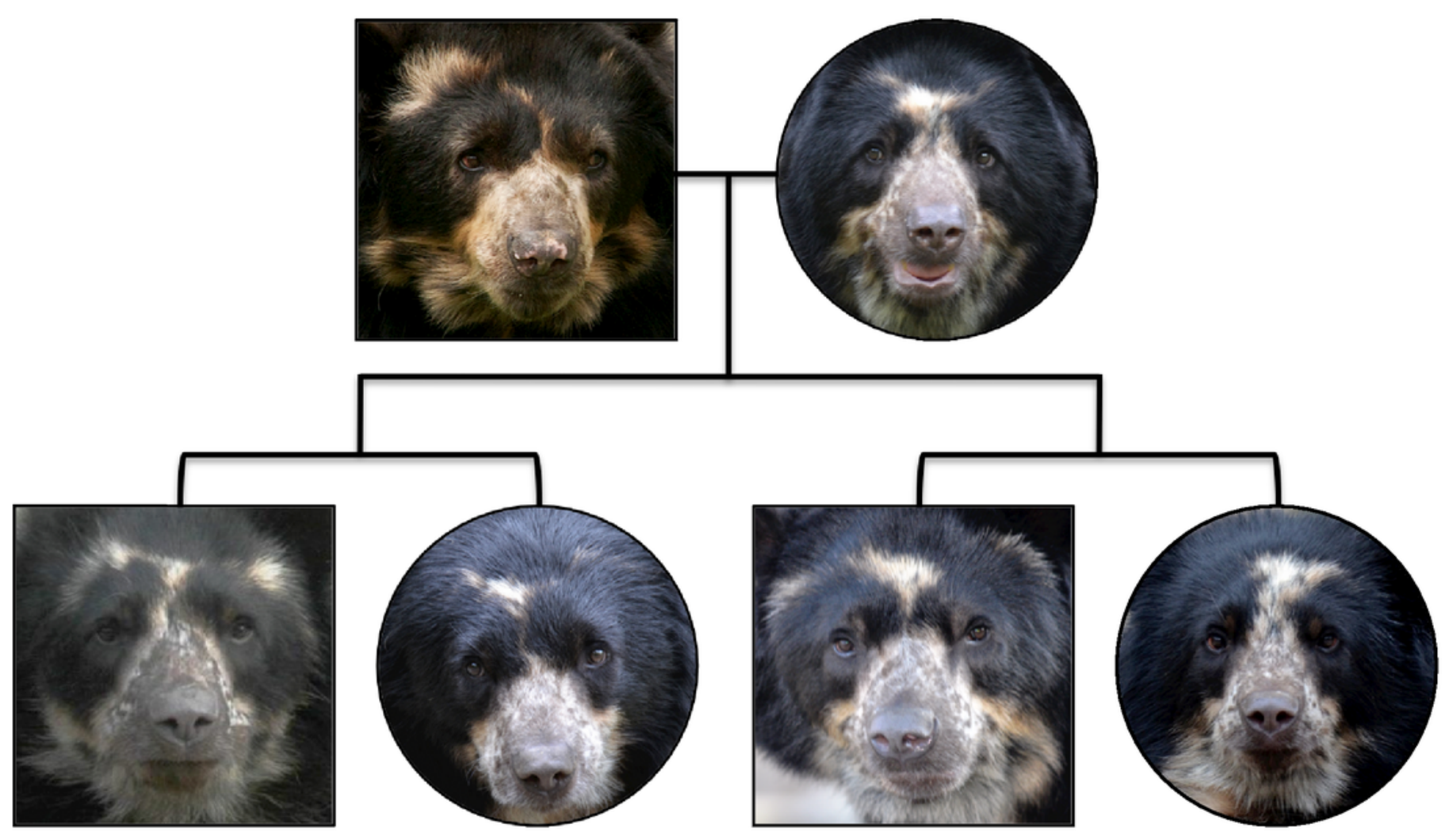

